\title{
Cystotoperitoneal shunt surgery during infancy in porencepahalic cyst located in frontal region led to regaining of developmental milestone
}

\author{
Guru Dutta Satyarthee ${ }^{1}$, \\ Luis Rafael Moscote-Salazar ${ }^{2}$, Amit Agrawal ${ }^{3}$ \\ 1 Department of Neurosurgery, Neurosciences Centre, AlIMS New \\ Delhi, INDIA \\ 2 Neurosurgeon-Critical Care Red Latino, Latin American Trauma \& \\ Intensive Neuro-Care Organization, Bogota, COLOMBIA \\ 3 Neurosurgery Department, Narayana Medical College Hospital, \\ Chinthareddypalem, Nellore, Andhra Pradesh, INDIA
}

\begin{abstract}
Porencepahalic cyst is considered as an extremely uncommon developmental disorder of the central nervous system, being characterized by the presence of a fluidfilled cysts or cavities located within the cerebral hemispheres. It can be associated with varied aetiology and can present with a spectrum of clinical presentation varying from asymptomatic to grossly spastic limbs, mental retardation, cognitive impairment and intractable seizure. Extensive Pubmed and Medline search did not yield any result when searched for term "infancy, porencepahalic cyst, cystoperitonreal shunt." However, clear guideline for management is still lacking. Authors report an interesting case of giant porencepahalic cyst located in the right frontal region in infancy and underwent cystoperitonreal shunt surgery, which lead to good outcome with remarkable recovery of delayed milestones with adequate scholastic performances along with marked diminution in the size of porencepahalic cyst.
\end{abstract}

\section{INTRODUCTION}

Porencepahalic cyst is considered as an extremely rarer encephalaomalatic disorder of the central nervous system characterized by the presence of a fluid-filled cavities or cysts. [1] It usually represents the end result of various types of the cerebral parenchymal injury, but can also be congenital developmental disorder, or consequences of intracerebral hemorrhage. [2,3] Author reports an interesting case of porencepahalic cyst located in the right frontal region, who underwent cystotoperitoneal shunt surgery, led to recovery of regressive milestones and currently child is extremely well scholastically at four years following CSF diversion surgery.

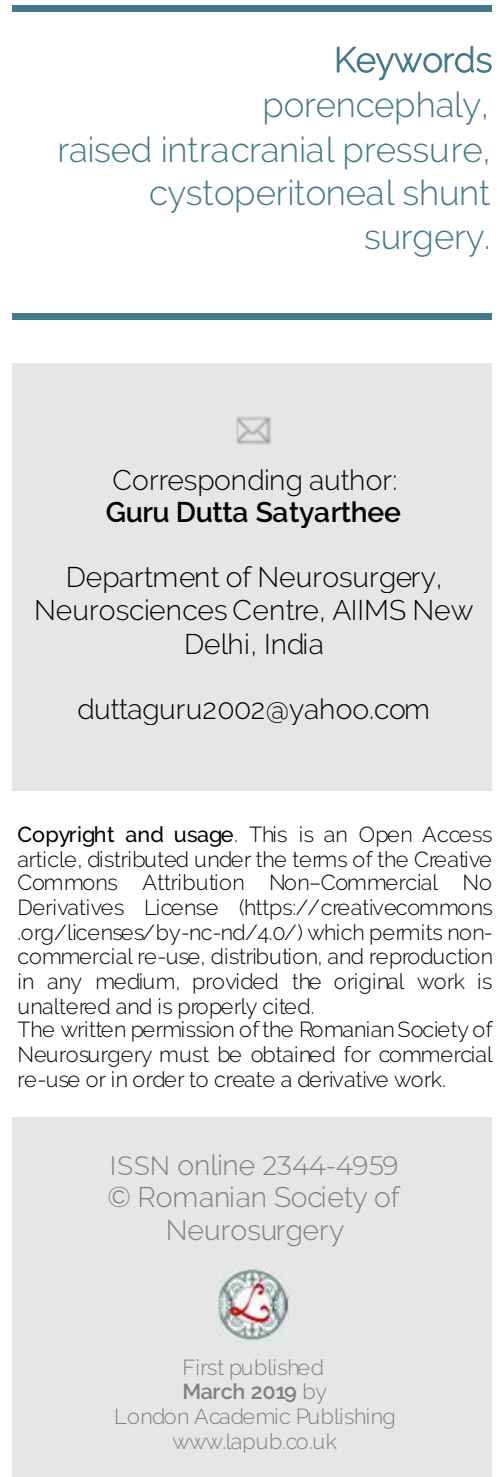




\section{CASE ILUSTRATION}

A one- year- old male infant was brought to our neuroscience emergency services with complaint of failure to thrive, delayed developmental milestones with repeated episodes of vomiting and progressive head enlargement for the last six months. On general physical examination at admission, vitals were stable, with bulging anterior frontanelle and head circumference was $54 \mathrm{~cm}$. On neurological examination, he was alert, crying. Evaluation of milestones, he was unable to can sit up without support and not able to crawl and could not use the pincer grasp. He was not able to begin to make recognizable syllables like "ma" and also had regression of language development. Fundi showed bilateral papilloedema. He had bilateral up gaze paresis with presence of sunset sign.

The routine hematological and biochemical parameters were normal limit. The computerized cranial tomography which was carried out after admission (Fig. 1) revealed presence of a giant porencepahalic cyst in the right frontal region

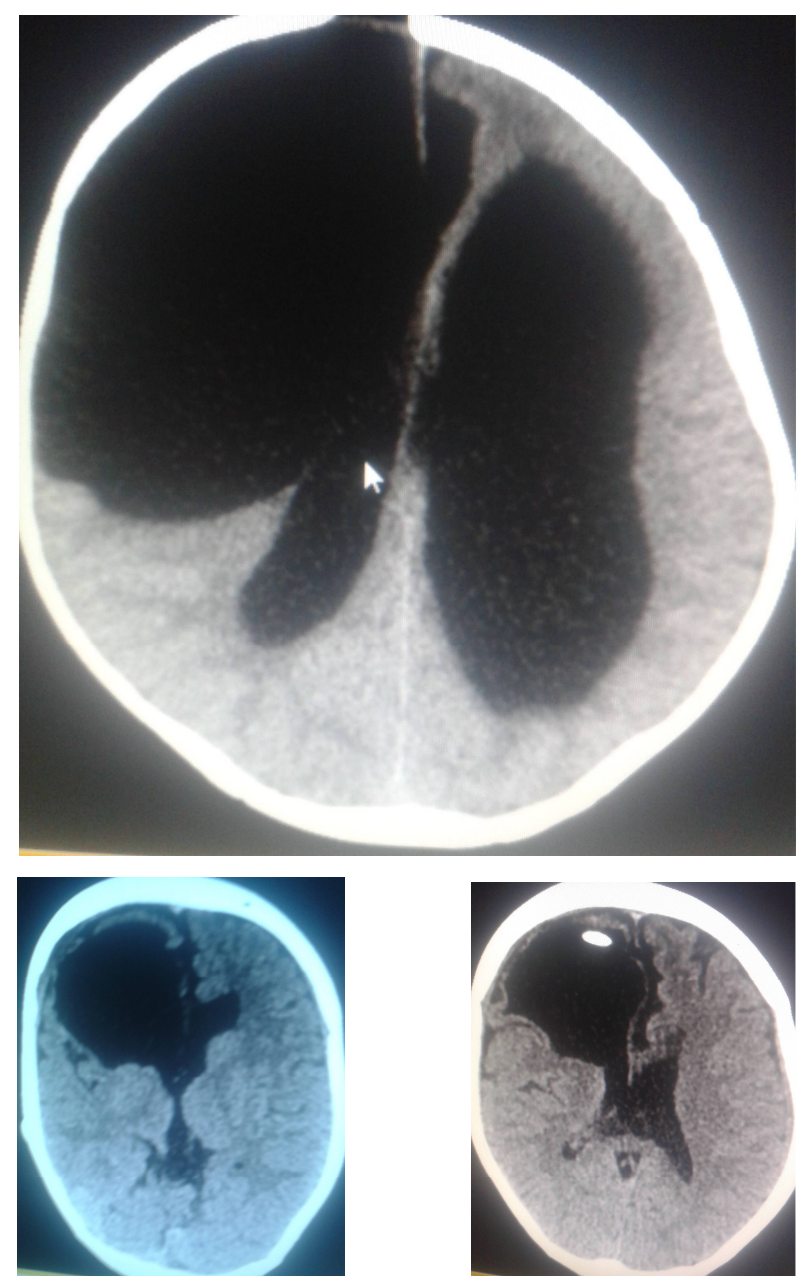

crossing across the midline and causing mass effect obstruction along the CSF pathway leading to dilated lateral ventricles, the third ventricle and. The periventricular ooze was present. (Fig. 2)

$\mathrm{He}$ underwent cysto-peritoneal shunt surgery under general anaesthesia. CSF study revealed normal biochemical parameters with normal cell count and further, CSF culture did not show growth of microorganism. After surgery he regained milestones like crawling, pincer grip and started telling Monosyllabic words over two months after the surgery. (Fig. 3)

The computerized tomography carried out at follow-up at four years after shunt surgery revealed well decompressed ventricles (Fig-4) with ventricular catheter well placed, (Fig. 5) and marked reduction in the size of porencepahalic cyst with well-functioning shunt. Follow-up at three year, he was doing extremely well with developmental milestone appropriate to age and the body weight also appropriate to the age.

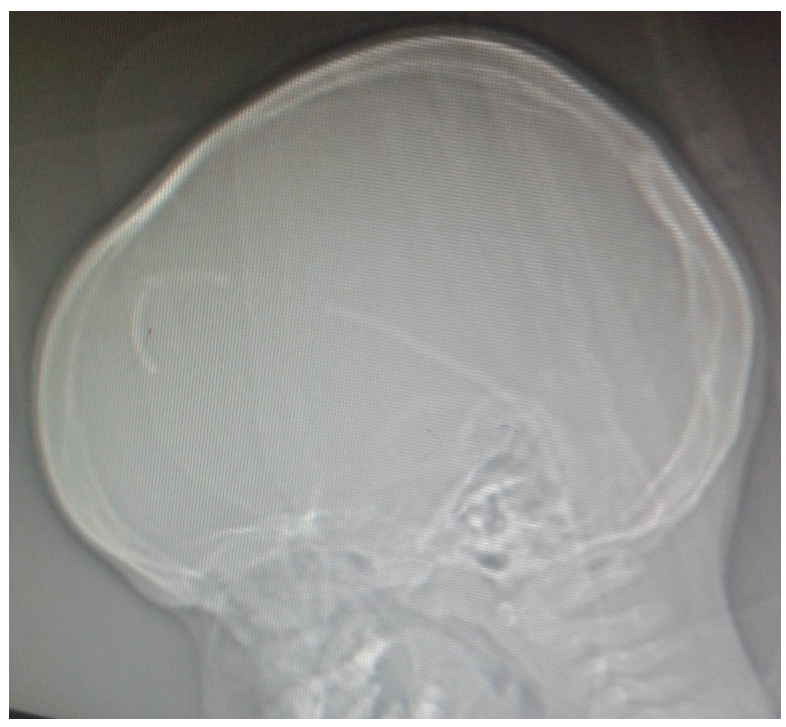

FIGURE 1. Noncontract cranial computed scan showing large porencepahalic cyst

\section{FIGURE 2. Tomogram showing shut in situ}

FIGURE 3. Noncontract cranial computed scan showing significant diminution in size of porencepahalic cyst

FIGURE 4. Noncontract cranial computed scan showing signicant diminution in size of porencepahalic cyst with shunt tip in situ 


\section{DISCUSSION}

In 1859, Heschl coined the term "porencephaly" to describe presence of a cavity within the human brain. [2] The porencepahalic cavities can result from focal cerebral degeneration secondary to haemorrhages. [8] further de novo or inherited heterozygous mutations in COL4A1 coding the type IV a1 collagen chain, which is essential for vascular basement membranes structural integrity is observed in individuals with porencephaly by Yonder et al. [8] Yoneda et al postulated abnormalities of the a1a1a2 heterotrimers of type IV collagen causes porencephaly. [4] During embryonic life. The large craters develop on the brain surface and gets lined with smooth tissue, filled -up with fluid and causes local mass effect and focal neurological deficit and regression of milestones. [5,6] Usually caused by antennal or perinatal insult prior to development of the cerebral gyri due to various pathology i.e. Infective, infarction ischemic or intracerebral haemorrhage.

Depending on the location, size and approximate to the vital region and severity of the defects, symptoms are highly variable and may cause only minor neurological deficit to severe mental retardation and paralysis in extreme cases. The patients with a porencepahalic cyst also frequently suffer with seizure disorder. [4,7]

The diagnosis can be also made even during antenatal period with ultrasound and considered as preferred imaging modality during fetal life. In infant, trans-illumination of the skull can also aid in the diagnosis of the porencepahalic cyst. Cranial computed tomography reveals location, size; volume, degree of mass effect, associated hydrocephalus and associated developmental pathology and effect of previous treatment and very useful in serial follow-up in assessing the size and evaluating the effect of cystoperitoneal shunt and recurrence of porencepahalic cyst. [6] Currently. The magnetic resonance imaging is considered as modalities of choice as it clearly depicts the pathology and associated obstruction along the CSF pathway and associated congenital hydrocephalus, agenesis of corpus callosum or other developmental pathology.

Porencepahalic cyst diagnosis requires detailed clinical and neurological evaluation, families history, clinical observations, or based on neuroimaging findings. Neuroimaging establishes the diagnosis and further assessment of intelligence, memory and speech evaluation can further aid in the planning of the holistic management and rehabilitation measures. [4]

Currently, there is no curative therapy for porencepahalic cyst and various treatments currently offered included physiotherapy for spastic limbs, rehabilitation, providing antiepileptic medication for those suffering with seizures. Surgical procedure may include cerebrospinal fluid diversion surgery like cystoperitonreal shunt, VP shunt surgery and surgery for epilepsy with intractable epilepsy. [1] According to the location of porencepahalic cyst, extent of the mass effect, size of cavities, and severity of the disorder, combinations of treatment modalities of treatment are usually made tailor made to suit the case.

Prognosis of porencephaly depending on various factors i.e. The location of the cyst and extent of the damage of the brain. Cases with mild neurological deficit can lead normal lives and self-care is possible, however more seriously disabled cases require lifelong support in the nursing care and rehabilitator measures. [5] Early diagnosis, medication, participation in rehabilitation activity related to fine-motor control, and communication skill can significantly improve the symptoms and ability to cope up with the severe disability and prompt to lead to normal life. Infants, with proper treatment, can develop good locomotors control as our case, as he was offered surgical treatment at infancy continued antiepileptic medication, led to good recovery of milestones and improvement in cognitive and scholastic performance.

\section{CONCLUSION}

Early diagnosis and management of symptomatic raised intracranial pressure in case of porencepahalic cyst, appropriate surgical intervention at early age and antiepileptic medication and rehabilitation measure and regular follow-up cases may aid in not only good neurological recovery and acquiring good motor and cognitive skill and can lead independent life as our cases underwent Cystoperitonreal shunt at one-year age.

\section{REFERENCES}

1. Gul A, Gungorduk K, Yildirim G, Gedikbasi A, Ceylan Y Prenatal diagnosis of porencephaly secondary to maternal 
carbon monoxide poisoning. Arch Gynecol Obstet. 2009; 279(5):697-700.

2. Hirowatari C, Kodama R, Sasaki Y, Tanigawa $Y$, Fujishima J, Yoshikawa T, Yabuuchi K, Kuwamura Y, Hirakawa K, Kamimura $\mathrm{Y}$, Maeda $\mathrm{H}$ Porencephaly in a cynomolgus monkey (macaca fascicularis). J Toxicol Pathol. 2012; 25(1):45-9.

3. Debus OM, Kosch A, Sträter R, Rossi R, Nowak-Göttl U The factor V G1691A mutation is a risk for porencephaly: A casecontrol study. Ann Neurol. 2004; 56(2):287-90.

4 Yoneda Y, Haginoya K, Arai H, Yamaoka S, Tsurusaki Y, Doi H, Miyake N, Yokochi K, Osaka H, Kato M, Matsumoto N, Saitsu $H$. De novo and inherited mutations in COL4A2, encoding the type IV collagen a 2 chain cause porencephaly. AmJ Hum Genet. 2012; 13; 90(1):86-90.

5 Shimizu M, Maeda T, Izumi T The differences in epileptic characteristics in patients with porencephaly and schizencephaly. Brain Dev. 2012; 34(7):546-52.
6. Ho SS, Kuzniecky RI, Gilliam F, Faught E, Bebin M, Morawetz $\mathrm{R}$ Congenital porencephaly and hippocampal sclerosis. Clinical features and epileptic spectrum. Neurology. 1997; 49(5):1382-8.

7. Burneo JG, Faught E, Knowlton RC, Martin RC, Bebin M, Morawetz R, Kuzniecky R Temporal lobectomy in congenital porencephaly associated with hippocampal sclerosis. Arch Neurol. 2003; 60(6):830-4.

8. Yoneda Y, Haginoya K, Arai H, Yamaoka S, Tsurusaki Y, Doi $\mathrm{H}$, Miyake N, Yokochi K, Osaka H, Kato M, Matsumoto N, Saitsu H De novo and inherited mutations in COL4A2, encoding the type IV collagen a 2 chain cause porencephaly. Am J Hum Genet. 2012 13; 90(1):86-90. 